\title{
Os novos programas de Física e Química A
}

\section{Resumo}

Este artigo pretende alertar para a organização dos novos programas de $10{ }^{\circ}$ e $11 .^{\circ}$ anos da disciplina de Física e Química A.
Não é uma exposição exaustivo dos pontos que considero incorrectos nos programas, mas apenas um comentário sucinto que me ocorre fazer após a leitura dos mesmos.
Ao ler a introdução ao programa de Fisica e Química A fica-se encantado. Finalmente vê-se escrita e sublinhada a obrigatoriedade de aulas prático-laboratoriais, com um máximo de 12 alunos, a presença de um técnico de laboratório e até especificações relativas ao horário dos alunos. Trata-se de meia página, que com um texto claro e objectivo, descreve aquilo que deve ser a abordagem da Física e da Química ao nível do Ensino Secundário.

O encanto quebra-se quando se lê o título da unidade 1 da componente de Química - Das Estrelas ao Átomo. Volta-se atrás, verifica-se o número da página, relê-se a citação inicial, que é do físico Steven Weinberg, pensa-se que algo não está no sítio. Avança-se umas páginas e em "Objecto de ensino" verifica-se que no ponto 1.1 se deve abordar a "Arquitectura do Universo", focando temas como a teoria do Big-Bang, escalas de tempo, aglomerados de estrelas, etc. Ainda não se acredita e avançam-se mais umas páginas à procura do desenvolvimento destes temas.

E a dúvida dissipa-se. Pretende-se mesmo a leccionação destes temas na sua essência. A pergunta que surge em seguida é: qual a forma adoptado pelos manuais para tal?

Abrem-se alguns manuais, aprovados (não sei por que entidade) e lá está des- crita a teoria do Big-Bang. Seguem-se as escalas de temperatura, tempo e comprimento em jeito de revisão, apresentando a unidade Kelvin para temperatura, como se a mesma já fizesse parte do saber adquirido dos alunos. Curiosamente mais tarde, na componente de Física, esta escala vai ser explicada como algo de novo. Também curiosamente todos os manuais exibem uma grande precisão na generalidade dos valores apresentados, excepto na conversão da escala Kelvin para a escala Celsius, em que apenas mostram o valor 273 como factor de conversão. Pergunto-me qual será nestas circunstâncias a diferença entre o ponto de fusão e o ponto triplo da água. Não sendo obviamente esta uma preocupação ao nível do $10{ }^{\circ}$ ano, é uma questão de rigor e correcção de aprendizagem.

Mais adiante nos manuais podemos aprender o que é um ano-luz e, em alguns, podemos até ficar a saber como se mede a distância a um astro pelo método de triangulação. Nascimento, vida e morte das estrelas e nucleossintese estrelar são outros dos temas que se podem desenvolver nesta unidade. O que são nebulosas e anãs brancas, pulsares e buracos negros, também se pode aprender aqui.

Não obstante o interesse que tais matérias suscitam nos jovens, elas enquadram-se na área da Física e não da Quí- mica. Mais concretamente numa subárea de nome Astronomia (de acordo com o que aprendi na faculdade). Sou a favor da interdisciplinariedade e pratico-a nas minhas aulas, mas isso não invalida o enquadramento correcto de cada tema numa determinada área do saber.

No programa segue-se um desenvolvimento de Química-Física, válido mas para o qual infelizmente os nossos alunos de $10 .^{\circ}$ ano não estão preparados, nem a nivel da química e da física nem a nível da matemática. Actualmente um jovem de 15 ou 16 anos não tem a capacidade de raciocínio abstrato desenvolvida para the permitir compreender a teoria atómica do ponto de vista da Química Quântica. Mesmo no $12 .^{\circ}$ ano, onde agora esta matéria é leccionada, as dificuldades são muitas. Está errado; a capacidade de abstracção deve ser trabalhada a nível do Ensino Básico, mas a realidade não é essa. Como é que se pode exigir a alguém que está habituado a trabalhar no concreto que de repente seja capaz de começar a quantificar átomos? Congratular-me-ia muito se estivesse enganada e, se no final do próximo ano lectivo, os nossos alunos tivessem adquirido as competências que são o objectivo deste programa.

Passemos à componente de Física. Inicia-se de forma muito mais suave do que a componente de Química. Aqui os alunos começam por estudar a energia 
repetindo o que aprenderam no Ensino Básico. Mas não nos iludemos; para que se fique bem consciente dos problemas ambientais do planeta devem-se aprender coisas como a lei de StefanBoltzmann, que tem um monte de letras esquisitas, aquelas que os professores dizem que são gregas, e um T à quarta, o tal da temperatura absoluta que ainda ninguém percebeu exactamente o que é (expectativa da visão dos alunos). Mas calma que a sua explicação há-de chegar. Entretanto há que aprender (fixar na óptica do aluno) mais umas quantas equações com muitas letras gregas e muitas potências e índices.

Não me vou alargar mais em exemplos do programa. Ele está disponível para todos, tal como os manuais. Também não vou comentar a carga horária semanal atribuída à disciplina de Fisica $\mathrm{e}$ Química $A$, nem a opção tomada para o actual ano lectivo de colmatar a falta de tempos lectivos nesta disciplina com os tempos atribuídos à disciplina de Técnicas Laboratoriais de Química, bloco I, porque a discussão de tais temas já atingiu a saturação sem que nada se tenha feito para emendar os erros.

A questão que coloco é a seguinte: trabalhamos tendo como primeiro objectivo a excelência do ensino das ciências ou a economia dos parceiros envolvidos?

Independentemente da minha opinião pessoal, considero que é necessária estabelecer um paradigma a longo prazo. A mudança constante de objectivos conduz à desmotivação de quem aplica os programas - os professores - e de quem os absorve - os alunos. A longo prazo duvido que os últimos adquiram uma sólida preparação para frequentar um curso superior na área das ciências, que é o objectivo da maioria.

A leitura pormenorizada dos programas de $10 .^{\circ}$ e $11 .^{\circ}$ anos da disciplina de Física e Química A e a preparação do programa de Química do $100^{\circ}$ ano, bem como a carga horária a eles destinada, suscitam-me as seguintes considerações:

- pretende-se que os alunos do Ensino Secundário adquiram uma consciência cientificamente fundamentada dos problemas ambientais que assolam o planeta, criando-lhe competências para, futuramente, actuarem sobre os mesmos ou pelo menos não contribuírem para a sua proliferação.

- pretende-se que estes alunos compreendam a importância da Química e da Física no desenvolvimento económico e social das comunidades.

- as opções tomadas para atingir os objectivos descritos acima, foram começar pelo topo da pirâmide e ir descendo, aos saltos para a base. Isto é, tentar partir do problema concreto e a partir dele descer ao nível da sua explicação teórica, abordando então uma série de conceitos fundamentais da Física e da Química, que se aplicam não só ao problema em questão mas à explicação de toda a estrutura do Universo. Os títulos das diversas unidades são disto ilustrativos.

- no meio de tentativa tão arrojada perdeu-se a noção do que se enquadra em cada área do saber e do nivel de desenvolvimento cognitivo do público alvo.

Não duvido das intenções nobres subjacentes à elaboração destes programas, mas não concordo com as estratégias escolhidas. Poder-se-ia atingir os mesmos objectivos, leccionando os mesmos conteúdos básicos, de forma mais equilibrada. Quando cheguei ao final da leitura do programa do $10 .^{\circ}$ ano formou-se na minha mente um organigrama totalmente diferente para alcançar a meta pretendida.

Considero que uma nova estrutura para estes programas não deve ser apresentada a título individual. Seria útil que os agentes propulsores do conhecimento da Física e da Química não se limitassem a contestar as directrizes que Ines chegam do Ministério da Educação, acabando sempre por tentar cumpri-las a qualquer preço, mas aplicassem os seus esforços elaborando propostas alternativas concretas. Fica lançado o desafio.

\section{Bibliografia:}

[1] Adelaíde Bello, Helena Caldeira, Ontem e Hoje, Fisica 10. ${ }^{\circ}$ ano, Porto Editora, 2003.
[2] Alda Pereira, Filomena Camões, Química, 10. ${ }^{\circ}$ ano, Texto Editora, 2003.

[3] Alexandre Costa, Ana M. Costa, Augusto M. F. Caeiro, VER + Fisica A $100^{\circ}$ ano, Plátano Editora, 2003

[4] Ana M. Morais, Conceição Lopes, Victor M. S. Gil, O Universo dos Átomos, Química 10. ${ }^{\circ}$ ano, Didática Editora, 2003.

[5] Carlos Corrêa, Adriano Nunes, Noémia Almeida, Quimica, $10{ }^{\circ}$ ano, Porto Editora, 2003.

[6] Daniel M. Silva, Desafios da Fisica, $10{ }^{\circ}$ ano, Lisboa Editora, 2003.

[7] Domitilia C. A. Menezes, Maria João M. Curto, Química $10{ }^{\circ}$ ano, Lisboa Editora, 2003.

[8] Graça Ventura, Manuel Fiolhais, Carlos Fiolhais, Joâo Paiva, António J. Ferreira, 10 F. Texto Editora, 2003.

[9] João Paiva, António J. Ferreira, Graça Ventura, Manuel Fiolhais, Carlos Fiolhais, 10 Q, Texto Editora, 2003.

[10] Isabel P. Martins, Helena Caldeira, et al, Programa de Fisica e Química A, $10^{\circ}$ ano, Ministério da Educação, DES, 2001.

[11] Isabel P. Martins, et al, Fisica e Quimica A, $11 .^{\circ}$ ano - Componente de Química, Projecto do Programa, Ministério da Educação, DES, 1. ${ }^{a}$ versã̃o, 2001.

[12] Lucinda S. Mendonça, Maria C. Dantas, Marta D. Ramalho, Jogo de Particulas, Quimica $10^{\circ}$ ano, Texto Editora, 2003.

[13] Luisa Melo, A Física no Nosso Mundo, $100^{\circ}$ ano, Constância 2003.

[14] Maria H. D. Silva, Maria P. M. Santos, José D. Silva, Velhos Rumos, Caminhos Outros - Quimica A $100^{\circ}$ ano, Plátano Editora, 2003.

[15] Maria M. R. D. Rodrigues, Fernando M. L. Dias, Fisica na Nossa Vida, $10 .^{\circ}$ ano, Porto Editora, 2003.

[16] Maria T. M. Sá, Física, $10^{\circ}$ ano, Texto Editora, 2003.

[17] Noémia Maciel, Maria J. Camponte, Maria M. Gradim Eu e a Química, $10^{\circ}$ ano, Porto Editora, 2003.

[18] Noémia Maciel, Maria M. Gradim, Maria J. Camponte Eu e a Física, $10{ }^{\circ}$ ano, Porto Editora, 2003.

[19] Teresa S. Simões, Maria A. Queirós, Maria Simões, Quimica em Contexto, $10^{\circ}$ ano, Porto Editora, 2003.

[20] Vera Daniel, A Química no Nosso Mundo, $10{ }^{\circ}$ ano, Constância, 2003. 